\title{
Manage with care: the frailty of self- connections in the European airport network
}

\author{
Mattia Cattaneo, Paolo Malighetti, Stefano Paleari and Renato Redondi
}

\begin{abstract}
This study evaluates the attractiveness of self-hubbing in terms of the (a) symmetry of itineraries and the consequences for passengers in the case of missed flights. We compute the most attractive European origin-destination (O-D) pairs through self-connection and evaluate their robustness by estimating the expected delays relative to connecting times and the travel options available when a connection is missed.

Results show that the potential of self-connecting markets is reduced when accounting for asymmetrical travel options and the consequences for travelers in the case of missed flights. In terms of frequencies, self-connecting passengers are, on average, found to have fewer alternatives to complete a given O-D pair than in the case of alliance-based connections (-33\%). Our findings moderate the confidence of past evidence on self-hubbing in light of the concrete reliability of selfconnections for passengers. The itinerary choice made by passengers inevitably depends on the evaluation of travel quality attributes related to the (a) symmetry of the itineraries and the costs incurred through missed connections.
\end{abstract}

Keywords: Indirect connectivity, European network, Minimum travel time; Robustness analysis

\section{Introduction}

With the development of the European air transportation market and the growth of low-cost carriers (LCCs), it has become possible for passengers to travel to a destination that is not directly handled by the airlines themselves through the self-connect option. This has become a concrete, alternative rather fly within Europe [7, 10, 17, 25].

In recent years, scholars have investigated the phenomenon of self-connectivity for passengers flying within the European air transportation network $[10,16$, $24,25,29,30]$, highlighting how it represents a concrete alternative for passengers. Malighetti et al. [25] show that, in 2006, up to two-thirds of the fastest indirect connections inside Europe were not operated by the airline alliances' system. Most recently, Cattaneo et al. [10] confirm that 1-transfer quickest paths achievable through selfconnecting flights in Europe have remained a valid alternative in the European framework over the last decade, increasing from $66 \%$ in 2006 to $69 \%$ in 2016 of the fastest

\footnotetext{
* Correspondence: renato.redondi@unibg.it Department of Management, Information and Production Engineering University of Bergamo, Bergamo, Italy
}

indirect connections inside Europe. The growing popularity of self-connectivity has been highlighted by the implementation of two systems for assisting self-connecting passengers between European airports, namely, ViaMilano at Malpensa airport in Milan and GatwickConnect at London Gatwick airport. Airlines have shown interest in this regard by providing passenger transfers between flights (Vueling, Norwegian, easyJet and Ryanair). Also, the development of IT platforms, such as Dohop and Kiwi, have facilitated passengers in approaching inter-connections.

Nevertheless, after a decade, some perplexities exist about the growth and sustainability of self-connections. On the one hand, airlines (both LCCs and traditional carriers) have been shown to be unable to fully exploit the opportunities generated by self-connections [31]. Indirect connections have reduced over time along with the fact that an increasing number of pairs have been directly connected by airlines [31]. Furthermore, the increasing establishment of LCCs in primary rather than in peripheral airports has inevitably hindered selfconnections over time [13]. On the other hand, airports have registered difficulties in sustainably implementing systems that manage all services associated with self- 
connections, such as dedicated areas for baggage transfer service and the management of insurance packages against the risk of missing flights [30]. Yet, the two cases generally mentioned by the literature, namely ViaMilano and GatwickConnect, have remained isolated examples in the European framework. Indeed, when an airport decides to actively facilitate self-connections, it remains open the issue of making aware passengers of these alternatives. ${ }^{1}$ The efficient promotion of these services requires a stronger cooperation with metasearch engines or airlines.

Though the literature has extensively shown the potential of self-connectivity inside the European air transportation market as an exciting opportunity in air transportation connectivity, its robustness in the eyes of passengers is yet to be demonstrated in detail. In this paper, we aim to analyze the extent to which the frailties of self-connections make them a non-valid alternative for European passengers who strategically evaluate whether to set up flight transfers themselves. This would contribute to a better understanding of the development of self-connection occurred over the last 10 years and under which conditions they would concretely benefit passengers and operators inside the market (airlines and airports) in the upcoming years.

For this purpose, the paper extensively investigates the reliability of self-connections for passengers. We consider quality attributes of self-connections, their performance in terms of travel times, and their robustness with respect to the offer made by airlines. We relied on the quickest travel time approach [25] in order to identify the fastest connections that remained un-managed ${ }^{2}$ over time in the European context. Specifically, we focus on 1-stop connections from EU airports in a typical off-peak week of the autumn schedule, from September 13th to 19th, 2016. We consider both the intra-European market and the market between the EU and major intercontinental destinations.

The remainder of the article is organized as follows. Section 2 provides a review of the literature. Section 3 describes the methodology. Section 4 presents the empirical analysis detailing the robustness analysis on the self-connecting scheduled travels and conclusions are drawn in Section 5.

\section{Literature review}

The significant growth of the air transportation market in the last two decades has made the efficient management of airline operations more complicated. The planning of which legs to operate and the optimization of fleet and crew assignment have become increasingly complex [3]. In terms of these dynamics that have necessitated

\footnotetext{
${ }^{1}$ Indeed, passengers do not generally depart/land in these airports, almost neglecting their existence.

${ }^{2}$ The airline does directly manage the risk associated to the interconnection.
}

the development of new approaches to systematize the management of airlines' and airports' daily activities, a significant effort has been made by scientific literature in developing more efficient and faster optimization approaches $[4,18]$. The satisfaction and loyalty of current travelers and the attraction of new ones are acknowledged as being critically influenced by on-time performances [1]. Punctuality and reliability are found to be among the most crucial factors affecting passengers' choices (e.g., $[2,15]$ ) Nevertheless, irregularities in airline schedules, namely the fact that every flight will not depart/arrive as planned, have become increasingly common and responsible for hasty connections and the increased risk of misconnection for passengers. These anomalies, which are generally due to weather conditions, high levels of congestions at airports, and unscheduled maintenance, represent critical issues, especially for connecting passengers $[6,22]$ who risk missing their connecting flight.

With regards to connectivity irregularities, the literature has largely investigated airlines' disruption management processes (see [21]), first focusing on the analysis of their causes, such as delay propagation (e.g., [12, 20, $28]$ ), and proposing integrated recovery plans to minimize inconveniences to passengers $([3,6,23]$;). Different solutions have been suggested, from preventively adding more time in airlines' schedules, that is, "schedule padding" [14], to increasing aircraft speed control [3, $11]$ and retiming departure times within a narrow timewindow [22]. However, the significant effort made by the literature in examining how to limit inconveniences to passengers and set up reliable schedules has left how much schedule disruptions may count for passengers travelling via self-connections unexplored. Compared to the connections operated by the alliances system, selfconnections are indeed exposed to a higher level of uncertainty due to the potential variation of the schedule on each leg without any assistance [16].

Both the nature and the development of the phenomenon (more than 2/3 of the fastest connections are today made through self-connectivity in the European network, as shown by [10]) entail a better understanding of whether these connections are reliable alternatives for passengers and which potential interventions should be implemented due to their sustainability.

\section{Methodology}

With the aim of investigating the robustness of selfconnections, our study aims to examine the following in depth: 1) their performance in terms of frequency and presence of reliable return flights; 2) to what extent the presence of delays on connecting legs could impact the performance of self-connection compared to other alternatives; 3 ) the impact of missing connecting legs in light of reaching the destination in reasonable time. 
The first step of our analysis is to identify all viable connections, including both alliance-coordinated and selfconnections. The volume of transit passengers may be considered as an alternative to identify connections already undertaken by passengers. However, the transit passenger volume for a specific origin-destination (O-D) pair is unknown for self-connecting passengers. The Marketing Information Data Tapes (MIDT) data, which provides information on passengers' bookings made by Global Distribution Systems (GDS), does not cover some of the major LCCs in Europe. However, even if it did, self-connecting passengers usually have to book the tickets for the different legs of their trip separately. In any case, it would not be possible to measure their volume using specific O-D pairs. Instead, we considered a supply-based measure of hubbing activities taken from the literature on the connectivity of air transport networks (see [9] for a review of the different measures in this field). We only focus on 1-stop connections and distinguish three categories of connections based on the kind of carriers involved:

- Alliance-based connection: The connection is between flights operated by carriers belonging to the same alliance;

- On-line connection: The connection is between flights operated by the same carrier, which is unallied but still a traditional carrier. An example of on-line connections is those involving the independent Gulf airlines such as Emirates and Etihad;

- Self-connection: The connection is not classified in the two previous groups. It involves a transfer between independently ticked flights operated by unrelated carriers, belonging to either different alliances, independent, or low-cost carriers.

Based on schedule information, we computed the number of "viable" connections between incoming and outgoing flights in a given airport. We included the following three conditions for a connection to be considered "viable":

- The time between the incoming and outgoing flights must be higher than a minimum connecting time (MCT). Table 1 reports the different assumed MCTs for the different connections and different geographical regions.

Table 1 Minimum connecting times for type of connections and for geographical areas

\begin{tabular}{lcc}
\hline $\begin{array}{l}\text { Minimum connecting } \\
\text { times (minutes) }\end{array}$ & $\begin{array}{c}\text { Intra-EU } \\
\text { connections }\end{array}$ & $\begin{array}{c}\text { Intercontinental } \\
\text { connections }\end{array}$ \\
\hline $\begin{array}{l}\text { Alliance-based and } \\
\text { on-line connections } \\
\text { Self-connections }\end{array}$ & 45 & 60 \\
\hline
\end{tabular}

- The routing factor of the one-stop itinerary starting from the origin of the incoming flight, passing through the considered airport, and arriving at the destination of the outgoing flight must be 1.4 or less for intra-European connections, and 1.2 or less for intercontinental connections [8]. The detour necessary to complete the trip must be at most $40 \%$ of the direct distance between the origin and destination in the case of EU connections, and 20\% in the case of intercontinental connections. This condition aims to exclude some low-quality O-D connections that are not attractive for passengers due to long detours, such as going from Rome to Barcelona via London.

- The quickest travel time is implemented following the minimum travel time approach ([26]; for a detailed explanation see [25], pp. 56), including both flight times and waiting times spent in the intermediate airport. It is computed for all O-D pairs that met the abovementioned two conditions. As in Redondi et al. [27], the last condition for a connection to be considered requires that its travel time does not exceed that of the quickest alternative by more than $40 \%$ in the case of EU connections and $20 \%$ in the case of intercontinental connections. This last condition discriminates the quality of connections by considering only those with the highest probability of being considered by passengers. It generally excludes connections with long waiting times spent in intermediate airports.

The analysis considers all scheduled flights operating in a typical off-peak period of the autumn schedule, from September 13th to 19th 2016, and computes all viable connections in that period. An off-peak week is chosen to identify connections that are persistent over time. Data on scheduled flights and airlines operating on each route were obtained from the Official Airline Guide (OAG) dataset.

After selecting all viable connections for passengers in the considered period, we measure some attributes, such as:

i) their time-performance with respect to the quickest alternatives;

ii) the weekly frequencies of connections;

iii) the feasibility of performing a return trip on the same day;

iv) the consequences for passengers of missing the firstleg flight (first flight of an itinerary composed involving one stop at the hub airport) of their trip in terms of increased waiting times and likelihood of not completing the trip on the same day and during $48 \mathrm{~h}$;

v) the consequences for passengers of missing the second-leg flight (second flight of an itinerary involving one stop at the hub airport) of their trip, in terms of increased waiting times and 
likelihood of not completing the trip on the same day and during $48 \mathrm{~h}$;

\section{Empirical analysis}

4.1 Connection performances

Table 2 reports the number of quickest connections by carrier type. Considering the percentage of viable 2-step connections with respect to all 2-step connections for geographical regions, $67.1 \%$ of all 2-step connections within Europe satisfy the conditions reported in the methodology section. Therefore, the remaining $32.9 \%$ are not considered in this analysis as they do not meet the quality criterion regarding the maximum routing factor (1.4) to connect O-D pairs. In the case of intercontinental connections, almost $50 \%$ of connections are excluded from the analysis. At a European level, $63.4 \%$ of 2-step connections are available through self-connection strategies, while the three alliances offer a combined total of just 34\% of 2-step connections. The relevance of self-connections decreases to $37.4 \%$ in the case of intercontinental destinations. Star Alliance is the leader on the intercontinental markets, with 23.2\%, followed by Skyteam and OneWorld.

Table 3 shows the performance, in terms of travel times, of the viable connections with respect to the quickest alternatives. Considering the intra-EU market, self-connections increase travel times above the quickest alternatives by an average of $15.8 \%$. This is mainly due to longer connecting times as self-connections are not planned by airlines and are often the result of the casual mixing of different, scheduled offers. Routing factors, defined as the sum of flight distances of the first and second leg flights divided by the direct distance between the origin and the destination airports, are very similar between alliance-based and selfconnections. Overall, the difference between the travel time performance of self-connections and connections offered within alliances is not as large as one would expect. OneWorld and Sky Team, the two best performing providers of 2-step connections in Europe, show an average increase in travel times above the quickest alternatives of $12.8-12.9 \%$. Only online connections provided by unallied traditional carriers show significantly better performances, but th ey only marginally cover the intra-EU market.

When looking at the intercontinental market, the most efficient 2-step connections are again those offered by unallied independent carriers, followed by Sky Team and Star Alliance, with average increases above the quickest connections of around 6-7\%. With respect to these, self-connections take around 3\% more travel time to be completed, with increases of $9.2 \%$ above the quickest options.

\subsection{Frequencies and return trip availability}

Table 4 compares the frequencies of connections offered by the alliances, online connections, and selfconnections. At a European level, viable self-connections link 18,515 different O-D pairs. On average, each of these connections is offered 7.7 times during the week considered in this analysis, which is more than once per day. The average connection frequency is 9.1 per week, while connections offered by SkyTeam reach 14.8 per week, more than twice a day. Self-connections are also offered with significantly lower frequencies for intercontinental destinations under alliance-based connections. Appendix 1 additionally reports numbers of viable connections of European O-D pairs at an airport level. Interestingly, the airports with the highest share of selfconnections are Oslo, Rome Fiumicino, Stockholm, Copenhagen, Barcelona, and London Gatwick. At an intercontinental level, the airports at the top of the ranking for self-connection opportunities are Rome Fiumicino, Copenhagen, and Dublin (see Appendix 2).

It is interesting to estimate if a viable connection for a given O-D pair can also be reverted, allowing passengers to make return trips. Table 5 compares the different kinds of connections over four different return trip scenarios.

Table 2 Number of quickest 2-step connections by type of connections and for geographical areas

\begin{tabular}{|c|c|c|c|c|}
\hline \multirow[t]{2}{*}{ Quickest 2-step connections by type } & \multicolumn{2}{|c|}{ Intra-EU } & \multicolumn{2}{|c|}{ Extra-EU } \\
\hline & No. & $\%$ & No. & $\%$ \\
\hline No. of 2-step indirect connections & 32,673 & & 10,308 & \\
\hline$\%$ of 2 -step viable connections & $67.1 \%$ & & $49.9 \%$ & \\
\hline Total no. of viable 2-step connections & 21,914 & $100 \%$ & 5142 & $100 \%$ \\
\hline \multicolumn{5}{|l|}{ Alliances } \\
\hline OneWorld & 2411 & $11.0 \%$ & 900 & $17.5 \%$ \\
\hline Sky Team & 1994 & $9.1 \%$ & 1136 & $22.1 \%$ \\
\hline Star Alliance & 3046 & $13.9 \%$ & 1193 & $23.2 \%$ \\
\hline Online & 789 & $3.6 \%$ & 77 & $1.5 \%$ \\
\hline Self-connection & 13,893 & $63.4 \%$ & 1923 & $37.4 \%$ \\
\hline
\end{tabular}


Table 3 Number of viable 2-step connections and their time-performance (Avg. time index: increase in travel times above the quickest alternatives), average connecting times and routing factors by type of connections and for geographical areas

\begin{tabular}{|c|c|c|c|c|c|c|}
\hline \multirow[t]{2}{*}{ Viable 2-step connections by type } & \multicolumn{3}{|c|}{ Intra-EU } & \multicolumn{3}{|c|}{ Extra-EU } \\
\hline & $\begin{array}{c}\text { Avg. } \\
\text { time index }\end{array}$ & Conn. time & Rout. Fact. & $\begin{array}{l}\text { Avg. } \\
\text { time index }\end{array}$ & Conn. time & Rout. Fact \\
\hline \multicolumn{7}{|l|}{ Alliances } \\
\hline OneWorld & $112.8 \%$ & 92.9 & 1.11 & $107.2 \%$ & 129.1 & 1.07 \\
\hline Sky Team & $112.9 \%$ & 89.0 & 1.11 & $106.6 \%$ & 123.0 & 1.07 \\
\hline Star Alliance & $114.6 \%$ & 87.3 & 1.11 & $106.8 \%$ & 121.4 & 1.06 \\
\hline Online & $108.4 \%$ & 114.0 & 1.10 & $106.2 \%$ & 141.3 & 1.03 \\
\hline Self-connect & $115.8 \%$ & 139.6 & 1.10 & $109.2 \%$ & 171.2 & 1.06 \\
\hline Total no. of viable 2-step connections & $114.7 \%$ & 116.2 & 1.11 & $107.7 \%$ & 140.8 & 1.06 \\
\hline
\end{tabular}

Scenario I: This scenario considers the daily return trip in which passengers spend at least $4 \mathrm{~h}$ at their destination and return to their origin airport. This is a typical scenario for business passengers. Interestingly, by employing self-connections, the likelihood of being able to make a return trip of this kind is only $9.2 \%$ given the total number of offered O-D pairs, as shown in Table 4. The Skyteam and Star alliances have much higher daily return trip ratios, $48.1 \%$ and $35.1 \%$, respectively. On average, when the daily round trip is feasible, there are 1.18 return options.

Scenario II: A daily round trip can be made in a city pair. This scenario is therefore less demanding than the previous one as it allows passengers to make the return trip by employing other O-D pairs, as long as they connect to the same cities. For example, a passenger may depart from London Gatwick to reach Catania airport via Rome Fiumicino. The return trip may be from Catania airport to London Stansted via Bergamo airport. However, even in this case, the number of city pairs that can be connected does not increase significantly with respect to the previous scenario. The return trip ratio of self-connections increases to $10.3 \%$. However, the same figure for SkyTeam and Star alliances is about four times as much, $48.5 \%$ and $35.6 \%$, respectively.
Scenario III: The return trip has to be made during the week and passengers spend at least $24 \mathrm{~h}$ at their destination. This scenario better represents the behavior of leisure passengers as well as that of business passengers. In this case, by self-connecting, passengers can make a round trip in $65.8 \%$ of all viable $\mathrm{O}-\mathrm{D}$ pairs. The difference between self-connection and other kinds of connections is relatively low in this scenario. However, when looking at the number of return options, the lower quality of self-connections becomes evident again. Self-connecting passengers have an average of 3.7 return options during the week, while Skyteam offers 7.87 options and Star offers 12.6 options. Scenario IV: Passengers are still allowed at least $24 \mathrm{~h}$ at a destination, but the one-way and return trips must be operated by the same carriers. This is a more demanding scenario than the previous one and measures the robustness of the round trip with respect to the choice of the carrier. Given the fact that even LCCs have recently begun to promote frequent flyer programs, in which they offer more booking flexibility and higher quality standards, business passengers may be interested in return trips operated by the same carriers. The performances of the different kinds of connections are similar to those related to the previous scenario; self-

Table 4 Number of viable connections, number of O-D pairs and average frequencies by connection type and geographical regions

\begin{tabular}{llccccccc}
\hline & & OneWorld & SkyTeam & $\begin{array}{c}\text { Star } \\
\text { Alliance }\end{array}$ & Online & $\begin{array}{c}\text { Self } \\
\text { connect }\end{array}$ & $\begin{array}{c}\text { Total } \\
\text { \% self } \\
\text { connect }\end{array}$ \\
\hline European & No. viable connect. & 27,586 & 41,293 & 52,995 & 4593 & 142,208 & 268,675 & $52.9 \%$ \\
& No. O-D pairs & 3367 & 2799 & 3802 & 969 & 18,515 & 29,452 & $62.9 \%$ \\
& Average freq. & 8.2 & 14.8 & 13.9 & 4.7 & 7.7 & 9.1 & $84.6 \%$ \\
Extra-EU & No. viable connect. & 17,139 & 25,368 & 26,790 & 607 & 38,610 & 108,514 & $35.6 \%$ \\
Connections & No. O-D pairs & 1591 & 1900 & 1809 & 138 & 3854 & 9292 & $41.5 \%$ \\
& Average freq. & 10.8 & 13.4 & 14.8 & 4.4 & 10.0 & 11.7 & $85.5 \%$ \\
Total & No. viable connect. & 44,725 & 66,661 & 79,785 & 5200 & 180,818 & 377,189 & $47.9 \%$ \\
Connections & No. O-D pairs & 4958 & 4699 & 5611 & 1107 & 22,369 & 38,744 & $57.7 \%$ \\
& Average freq. & 9.0 & 14.2 & 14.2 & 4.7 & 8.1 & 9.7 & $83.5 \%$ \\
\hline
\end{tabular}


Table 5 Number of O-D pairs with return trips i) during the day with at least $4 \mathrm{~h}$ at destination, ii) during the day with at least $4 \mathrm{~h}$ at destination at city pairs, iii) with at least $24 \mathrm{~h}$ at destination and iv) with at least $24 \mathrm{~h}$ at destination and both the one-way and return trips operated by the same carriers

\begin{tabular}{|c|c|c|c|c|c|c|c|}
\hline & & OneWorld & SkyTeam & $\begin{array}{c}\text { Star } \\
\text { Alliance }\end{array}$ & Online & $\begin{array}{c}\text { Self } \\
\text { connect }\end{array}$ & Total \\
\hline \multirow{3}{*}{$\begin{array}{l}\text { Scenario } 1 \\
\text { Daily return trip } \\
\text { (al least } 4 \mathrm{~h} \\
\text { at destination) }\end{array}$} & O-D pairs & 603 & 1347 & 1335 & 112 & 1698 & 5095 \\
\hline & \% O-D linked & $17.9 \%$ & $48.1 \%$ & $35.1 \%$ & $11.6 \%$ & $9.2 \%$ & $17.3 \%$ \\
\hline & No. return options & 1.18 & 0.93 & 1.34 & 0.80 & 1.09 & 1.18 \\
\hline \multirow{3}{*}{$\begin{array}{l}\text { Scenario } 2 \\
\text { Daily return trip at } \\
\text { city-pairs (al least } 4 \\
\text { hours at destination) }\end{array}$} & City pairs & 624 & 1354 & 1352 & 113 & 1913 & 5356 \\
\hline & $\%$ City linked & $18.5 \%$ & $48.4 \%$ & $35.6 \%$ & $11.7 \%$ & $10.3 \%$ & $18.2 \%$ \\
\hline & No. return options & 1.25 & 1.11 & 1.37 & 0.84 & 1.08 & 1.25 \\
\hline \multirow{3}{*}{$\begin{array}{l}\text { Scenario } 3 \\
\text { Return trip } \\
\text { (al least } 24 \mathrm{~h} \\
\text { at destination) }\end{array}$} & O-D pairs & 2496 & 2531 & 3018 & 587 & 12,184 & 20,816 \\
\hline & $\%$ O-D linked & $74.1 \%$ & $90.4 \%$ & $79.4 \%$ & $60.6 \%$ & $65.8 \%$ & $70.7 \%$ \\
\hline & No. return options & 8.87 & 7.87 & 12.60 & 6.47 & 3.70 & 8.87 \\
\hline \multirow{3}{*}{$\begin{array}{l}\text { Scenario } 4 \\
\text { Return trip } \\
\text { (at least } 24 \mathrm{~h} \\
\text { at destination) - } \\
\text { same carriers }\end{array}$} & O-D pairs & 2427 & 2519 & 2982 & 568 & 10,096 & 18,592 \\
\hline & \% O-D linked & $72.1 \%$ & $90.0 \%$ & $78.4 \%$ & $58.6 \%$ & $54.5 \%$ & $63.1 \%$ \\
\hline & No. return options & 5.13 & 2.35 & 8.65 & 5.49 & 3.82 & 5.13 \\
\hline
\end{tabular}

connection passengers have only 3.82 return options available. The exception to this is the Star alliance, whose return travel options are 8.65 on average, almost double that of the other groups.

\subsubsection{The impact of delayed flights and missed connections/ flights}

After having studied some quality attributes of the offer of self-connections, we aim to assess the impact of adverse events such as delayed flights, missed connections, and missed flights either in the first or second leg of the trip. ${ }^{3}$

We first aim to estimate the robustness of the connections subjected to delays in the incoming flights at intermediate airports. Table 6 and Fig. 1 report the percentage of missed EU connections when the incoming flight from the origin airport is delayed. Overall, in the event of a 30min delay of the incoming flight at the hub, in $40.3 \%$ of connections, passengers miss the outgoing flights to their final destinations. Interestingly, figures for alliance-based and self-connections are very similar. However, in the case of alliance-based connections, the percentages of missed flights may be overestimated as outgoing flights may wait for the delayed connecting passengers.

Table 7 and Fig. 2 show the percentage of missed extra-EU connections when the incoming flight from the origin airport is delayed. In this case, the probability of self-connecting passengers missing flights is significantly higher than for alliance-based passengers, even for a 10min delay; $13.5 \%$ for self-connect against $7.8 \%$ for

\footnotetext{
${ }^{3}$ The analysis of the "risk of missing a connection" does not account for the fact that passengers could not opt for the shortest connection time because of the risk of missing the connection itself.
}

OneWorld, $8 \%$ for Star, and 8.1\% for Skyteam. This difference increases to $10-15 \%$ when the incoming flights are delayed by more than $40 \mathrm{~min}$. Possible reasons are related to the higher minimum connecting time set for self-connecting passengers to extra-EU destinations (see Table 1) together with the absence of schedule coordination between short- and long-haul flights.

The next part of the empirical analysis estimates the robustness of the viable connections in the case of missed (or cancelled) flights. We aim to evaluate the consequences for passengers when the first-leg flight and the second-leg flight of the trip is missed, in terms of availability of backups and related delays.

shows the consequences for passengers when the firstleg flight of the trip is missed. Missing the first-leg flight may be the result of passengers' delays in assessing the airport, delays going through check-in and security procedures, or even due to the cancellation of the flight. In any case, passengers need to find an alternative path to reach their destination. This may not be possible when either the origin or the destination airports have a very limited offer.

In the case of European connections, on average, only $69.2 \%$ of viable O-D pairs can be successfully completed in $48 \mathrm{~h}$ after missing the first flight of the path. The highest backup ratios are for the three alliances with values generally above $80 \%$. When looking at average delays at destination, the spread between alliance connections and self-connections significantly increases. In terms of their original scheduled times, SkyTeam and Star Alliance can convey passengers to their destinations with 12 and $10.8 \mathrm{~h}$ of a delay, respectively. In the case of online and self-connections, that figure is above $19 \mathrm{~h}$. 
Table 6 Percentage of missed connections to EU destinations related to delayed arrivals at intermediate airports

\begin{tabular}{|c|c|c|c|c|c|c|}
\hline \multirow[t]{2}{*}{ EU connections } & \multicolumn{6}{|c|}{ Delayed arrival at the intermediate airports (minutes) } \\
\hline & 10 & 20 & 30 & 40 & 50 & 60 \\
\hline \multicolumn{7}{|l|}{ Alliances } \\
\hline OneWorld & $13.5 \%$ & $27.0 \%$ & $38.5 \%$ & $50.0 \%$ & $58.8 \%$ & $67.9 \%$ \\
\hline SkyTeam & $13.0 \%$ & $26.1 \%$ & $39.0 \%$ & $51.0 \%$ & $61.6 \%$ & $70.8 \%$ \\
\hline Star Alliance & $13.8 \%$ & $26.6 \%$ & $39.5 \%$ & $51.7 \%$ & $62.6 \%$ & $72.2 \%$ \\
\hline Online & $21.5 \%$ & $34.5 \%$ & $43.9 \%$ & $51.4 \%$ & $58.6 \%$ & $63.1 \%$ \\
\hline Self-connect & $14.5 \%$ & $28.3 \%$ & $41.1 \%$ & $52.8 \%$ & $62.6 \%$ & $70.7 \%$ \\
\hline Total connections & $14.2 \%$ & $27.7 \%$ & $40.3 \%$ & $52.0 \%$ & $62.0 \%$ & $70.6 \%$ \\
\hline
\end{tabular}

Therefore, in the latter cases, even if a backup trip is still possible, passengers arrive at destination almost on average 1 day after they had planned to do so.

In fact, when looking at the percentage of O-D pairs on which trips can still be completed on the same day, self-connections have the lowest value at $25.6 \%$, compared to 52.4\% for SkyTeam and 59.3\% for Star Alliance.

The previous results are confirmed even when intercontinental destinations are taken into consideration. Self-connections trail well behind alliance connections both in terms of backup ratios and average delays at destinations.

Table 9 reports the effects for passengers in the case of missing the second-leg flight of the trip. This is the most likely scenario as the missed connection at the intermediate airport may be the result not just of the cancellation of the outgoing flight, but also of excessive delays in the incoming flight or in going through security checks, baggage handling, and check-in for final destination. Passengers may be required to undergo the latter activities in the case of self-connections. For this reason, we considered a higher minimum connecting time for these kind of connections (see Table 1).
When compared with missing the first-leg flight of the trip, one would expect to find a higher degree of success in this scenario and fewer delays in reaching the final destination as the first half of the trip has already been completed. However, this is not always the case. When missing the first-leg flight of the trip, a passenger may be routed through a different intermediate airport in order to reach the final destination. If a connection is missed at the intermediate airport, passengers generally have to wait for another flight to their destination. If the destination airport is not frequently operated, this may result in the impossibility to complete the trip within 48 $\mathrm{h}$, or during severe delays.

In terms of European O-D pairs, self-connections have a backup ratio of $76.9 \%$, which is less than the overall average of $82.6 \%$. In other words, if they miss the second-leg flight of their trip, in more than eight out of ten cases, self-connecting passengers can reach their final destination within $48 \mathrm{~h}$. This is still a significantly higher value than the backup ratio (56.5\%) when the first-leg flight of the trip is missed, as shown in Table 8 . The same difference characterizes the percentage of travels completed in the day when missing the first or

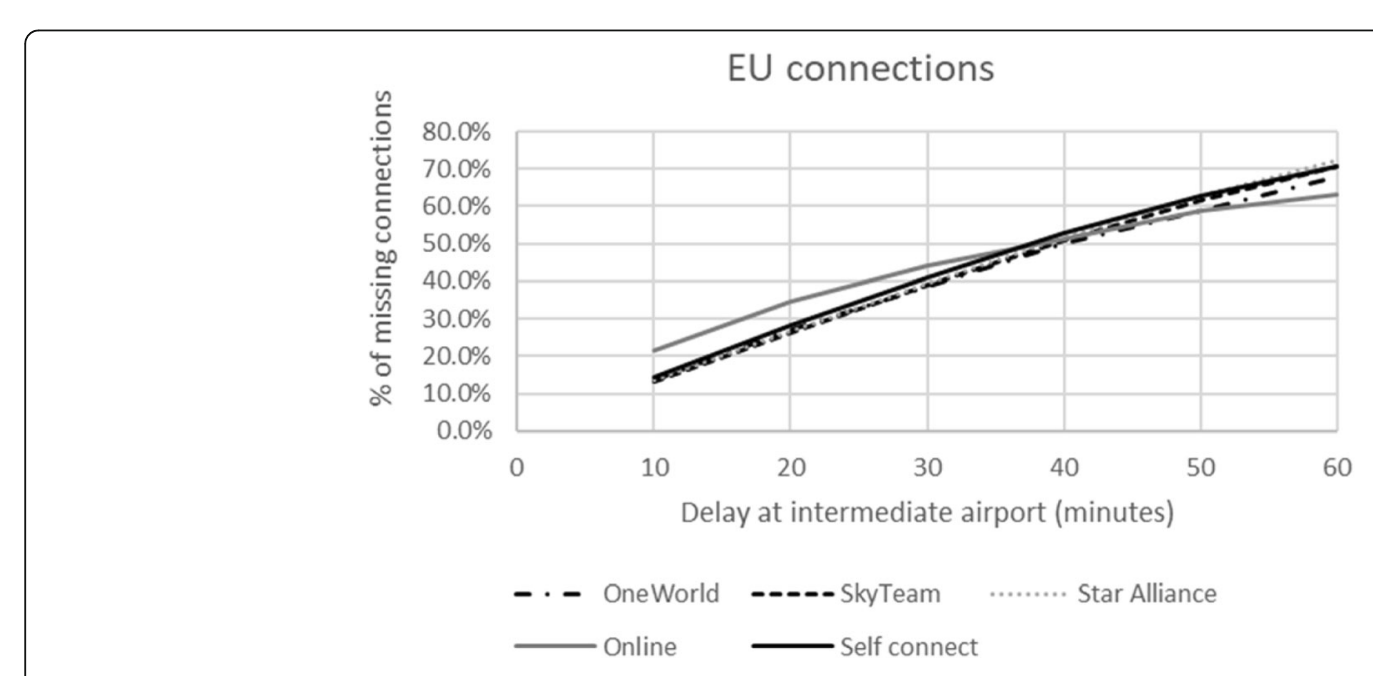

Fig. 1 Percentage of missed connections to EU destinations related to delayed arrivals at the intermediate airports 
Table 7 Percentage of missed connections to extra-EU destinations related to delayed arrivals at intermediate airports

\begin{tabular}{|c|c|c|c|c|c|c|}
\hline \multirow{2}{*}{$\begin{array}{l}\text { Extra-EU } \\
\text { connections }\end{array}$} & \multicolumn{6}{|c|}{ Delayed arrival at the intermediate airports (minutes) } \\
\hline & 10 & 20 & 30 & 40 & 50 & 60 \\
\hline \multicolumn{7}{|l|}{ Alliances } \\
\hline OneWorld & $7.8 \%$ & $15.7 \%$ & $23.7 \%$ & $31.8 \%$ & $39.3 \%$ & $48.1 \%$ \\
\hline SkyTeam & $8.1 \%$ & $16.7 \%$ & $26.3 \%$ & $36.0 \%$ & $46.0 \%$ & $55.5 \%$ \\
\hline Star Alliance & $8.0 \%$ & $16.7 \%$ & $26.1 \%$ & $36.3 \%$ & $45.7 \%$ & $54.6 \%$ \\
\hline Online & $5.6 \%$ & $10.2 \%$ & $18.9 \%$ & $24.1 \%$ & $29.0 \%$ & $31.8 \%$ \\
\hline Self-connect & $13.5 \%$ & $25.2 \%$ & $36.5 \%$ & $46.4 \%$ & $55.9 \%$ & $64.4 \%$ \\
\hline Total connections & $10.6 \%$ & $20.5 \%$ & $30.4 \%$ & $39.9 \%$ & $49.1 \%$ & $57.8 \%$ \\
\hline
\end{tabular}

the second-leg flight of the trip, from $25.6 \%$ to $48.6 \%$. Alliance connections are more reliable, even in this scenario, with backup ratios ranging from $87.9 \%$ for Star to 91.5\% for SkyTeam. Delays at destination when the connection can be successfully completed are equal to 12.1 $\mathrm{h}$ for self-connections, and between 7.2 and $8.5 \mathrm{~h}$ for alliance connections. The share of trips that can be successfully completed in the same day as planned is significantly lower for self-connections, which is $48.6 \%$, when compared with values ranging from $63.7 \%$ to $70.2 \%$ in the case of alliance connections.

The lower robustness of self-connections compared to alliance connections is confirmed even when evaluating extra-European O-D pairs. In this case, the successful backup ratios are lower and average delays are higher than in the intra-EU market, as one would expect, as passengers miss their intercontinental flight.

\section{Conclusion and discussion}

Overall, self-connectivity represents a significant opportunity for passengers, especially at a European level. Most of the viable connections in Europe
(63.4\%) can be successfully completed outside of the alliance or traditional carrier networks (2-step quickest connections). Even considering extra-EU connections, $37.4 \%$ of all viable connections are selfconnections. However, self-connectivity has some limitations, mainly due to the absence of coordination between carriers.

- Self-connections take longer to be completed in terms of the quickest alternatives, and also with respect to the other kinds of connections (see Table 3), even if their differences in travel times range from $2 \%$ to $3 \%$, which is much less than one would expect.

- In terms of frequencies, self-connecting passengers have, on average, fewer alternatives to complete a given O-D pair than in the case of alliance-based connections. The difference in their frequencies is generally around 33\% (see Table 4).

- Self-connections lag well behind other kinds of connections in case of daily return trips. This is mainly due to the fact that self-connections are

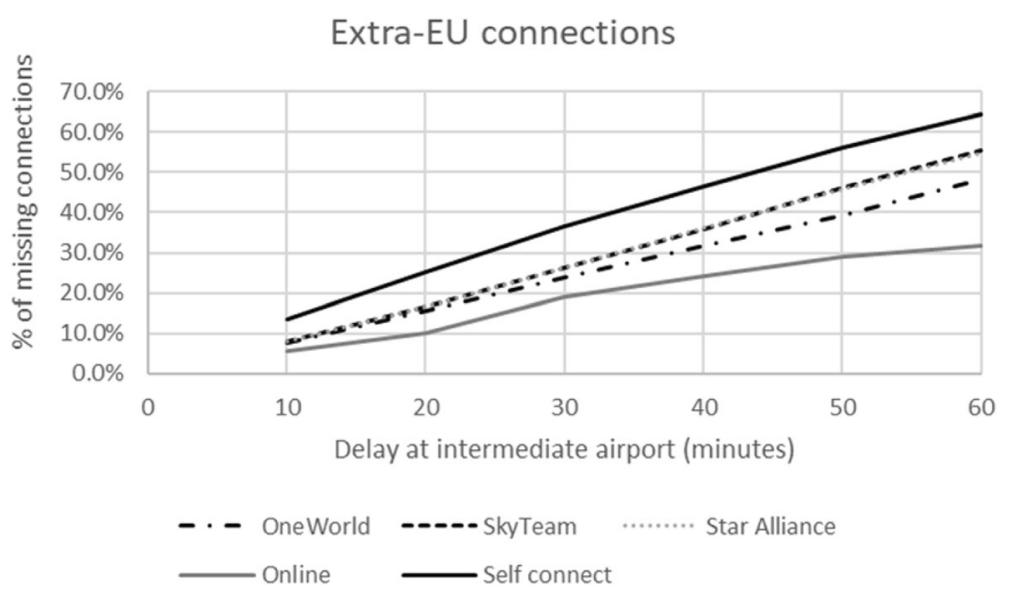

Fig. 2 Percentage of missed connections to extra-EU destinations related to delayed arrivals at the intermediate airports 
generally not symmetric and are therefore unlikely to allow completion of a round trip, especially during a day (see Table 5).

- When considering round trips in which passengers spend at least 1 day at their destination, the difference between self-connections and alliancebased connections is significantly reduced. However, in the latter case, there are at least twice as many options available for passengers for the return trip compared to self-connections.

- The percentage of missed connections to extra-EU destinations when the incoming flights are delayed is significantly higher for self-connecting passengers.

- The higher frailty of self-connections is also evident while examining consequences for passengers who missed a flight in their trip. If selfconnecting passengers miss the first-leg flight of their trip, the probability of reaching the final destination is reduced in comparison to other kinds of connections. Even in cases where selfconnecting passengers can reach the final destination within $48 \mathrm{~h}$, the incurred delays are almost double that of other types of connections.
Passengers generally arrive at a destination about $21 \mathrm{~h}$ after they had planned to do so (see Table 8).

- Similar results are obtained in the scenario of passengers missing the second-leg flight of their trip. Even if the advantages of alliance-based connections are reduced in comparison to the previous case, the risk of not making the O-D trip within $48 \mathrm{~h}$, and the incurred delays are still significantly higher for self-connections than for alliance connections (see Table 9).

Overall, even if the literature has extensively depicted self-connectivity as a great opportunity for passengers to connect inside the European air transportation market $[10,25]$, our evidence highlights that its potential is subject to the distinct possibility of passengers reaching the destination in a practicable way, thereby reducing their perceived risk before booking. Nowadays, the tools implemented for facilitating self-connections are scarce and concentrated in a few airports (ViaMilano in Malpensa and GatwickConnects in London Gatwick) where specific

Table 8 Number of travels completed and delay at destination in case of missed the first-leg flight by connection type and geographical regions

\begin{tabular}{|c|c|c|c|c|c|c|}
\hline Missing first-step flight & OneWorld & SkyTeam & $\begin{array}{c}\text { Star } \\
\text { Alliance }\end{array}$ & Online & $\begin{array}{c}\text { Self } \\
\text { connect }\end{array}$ & Total \\
\hline \multicolumn{7}{|l|}{ European Connections } \\
\hline No. travels completed & 21,968 & 36,767 & 43,600 & 3153 & 80,400 & 185,888 \\
\hline$\%$ of total O-D connections & $79.6 \%$ & $89.0 \%$ & $82.3 \%$ & $68.6 \%$ & $56.5 \%$ & $69.2 \%$ \\
\hline Delay at destination (h) & 14.6 & 12.0 & 10.8 & 19.2 & 20.9 & 16.0 \\
\hline Path completed in the day & 10,083 & 19,281 & 25,839 & 991 & 20,543 & 76,737 \\
\hline$\%$ of travels completed & $45.9 \%$ & $52.4 \%$ & $59.3 \%$ & $31.4 \%$ & $25.6 \%$ & $41.3 \%$ \\
\hline Delay at destination (h) & 4.8 & 5.6 & 4.2 & 5.7 & 4.8 & 4.8 \\
\hline \multicolumn{7}{|l|}{ Extra-EU Connections } \\
\hline No. travels completed & 12,853 & 20,030 & 19,660 & 444 & 24,899 & 77,886 \\
\hline$\%$ of total O-D connections & $75.0 \%$ & $79.0 \%$ & $73.4 \%$ & $73.1 \%$ & $64.5 \%$ & $71.8 \%$ \\
\hline Delay at destination (h) & 17.4 & 18.3 & 15.7 & 25.0 & 22.6 & 18.9 \\
\hline Path completed in the day & 3933 & 5280 & 7159 & 48 & 3714 & 20,134 \\
\hline$\%$ of travels completed & $30.6 \%$ & $26.4 \%$ & $36.4 \%$ & $10.8 \%$ & $14.9 \%$ & $25.9 \%$ \\
\hline Delay at destination (h) & 6.8 & 5.5 & 4.5 & 16.1 & 5.2 & 5.3 \\
\hline \multicolumn{7}{|l|}{ Total Connections } \\
\hline No. travels completed & 34,821 & 56,797 & 63,260 & 3597 & 105,299 & 263,774 \\
\hline$\%$ of total O-D connections & $77.9 \%$ & $85.2 \%$ & $79.3 \%$ & $69.2 \%$ & $58.2 \%$ & $69.9 \%$ \\
\hline Delay at destination (h) & 15.6 & 14.3 & 12.4 & 19.9 & 21.3 & 16.9 \\
\hline Path completed in the day & 14,016 & 24,561 & 32,998 & 1039 & 24,257 & 96,871 \\
\hline$\%$ of travels completed & $40.3 \%$ & $43.2 \%$ & $52.2 \%$ & $28.9 \%$ & $23.0 \%$ & $36.7 \%$ \\
\hline Delay at destination (h) & 5.4 & 5.6 & 4.2 & 6.2 & 4.9 & 4.9 \\
\hline
\end{tabular}


Table 9 Number of travels completed and delay at destination in case of missed the second-leg flight by connection type and geographical regions

\begin{tabular}{|c|c|c|c|c|c|c|}
\hline Missing second-step flight & OneWorld & SkyTeam & $\begin{array}{c}\text { Star } \\
\text { Alliance }\end{array}$ & Online & $\begin{array}{c}\text { Self } \\
\text { connect }\end{array}$ & Total \\
\hline \multicolumn{7}{|l|}{ European Connections } \\
\hline No. travels completed & 24,300 & 37,787 & 46,597 & 3919 & 109,425 & 222,028 \\
\hline$\%$ of total O-D connections & $88.1 \%$ & $91.5 \%$ & $87.9 \%$ & $85.3 \%$ & $76.9 \%$ & $82.6 \%$ \\
\hline Delay at destination (h) & 8.5 & 7.7 & 7.2 & 12.7 & 12.1 & 9.9 \\
\hline Path completed in the day & 15,472 & 24,337 & 32,691 & 1884 & 53,232 & 127,616 \\
\hline$\%$ of travels completed & $63.7 \%$ & $64.4 \%$ & $70.2 \%$ & $48.1 \%$ & $48.6 \%$ & $57.5 \%$ \\
\hline Delay at destination (h) & 4.0 & 4.3 & 3.8 & 4.8 & 4.1 & 4.1 \\
\hline \multicolumn{7}{|l|}{ Extra-EU Connections } \\
\hline No. travels completed & 13,463 & 20,426 & 19,774 & 520 & 29,110 & 83,293 \\
\hline$\%$ of total O-D connections & $78.6 \%$ & $80.5 \%$ & $73.8 \%$ & $85.7 \%$ & $75.4 \%$ & $76.8 \%$ \\
\hline Delay at destination (h) & 16.7 & 18.0 & 20.8 & 19.4 & 21.2 & 19.6 \\
\hline Path completed in the day & 4479 & 5387 & 2763 & 104 & 5025 & 17,758 \\
\hline$\%$ of travels completed & $33.3 \%$ & $26.4 \%$ & $14.0 \%$ & $20.0 \%$ & $17.3 \%$ & $21.3 \%$ \\
\hline Delay at destination (h) & 11.3 & 7.3 & 12.3 & 19.4 & 11.0 & 10.2 \\
\hline \multicolumn{7}{|l|}{ Total Connections } \\
\hline No. travels completed & 37,763 & 58,213 & 66,371 & 4439 & 138,535 & 305,321 \\
\hline$\%$ of total O-D connections & $84.4 \%$ & $87.3 \%$ & $83.2 \%$ & $85.4 \%$ & $76.6 \%$ & $80.9 \%$ \\
\hline Delay at destination (h) & 11.5 & 11.3 & 11.2 & 13.5 & 14.0 & 12.6 \\
\hline Path completed in the day & 19,951 & 29,724 & 35,454 & 1988 & 58,257 & 145,374 \\
\hline$\%$ of travels completed & $52.8 \%$ & $51.1 \%$ & $53.4 \%$ & $44.8 \%$ & $42.1 \%$ & $47.6 \%$ \\
\hline Delay at destination (h) & 5.6 & 4.8 & 4.5 & 5.6 & 4.7 & 4.8 \\
\hline
\end{tabular}

platforms have been established to facilitate passenger transfers by avoiding the necessity of exiting controlled areas and directly managing baggage.

Along with the role that self-connectivity may play inside the European context over the coming years, especially considering that more than two-thirds of the fastest indirect connections inside Europe are not even operated by the alliances system, it would be crucial to identify solutions that are able to reduce passengers' risk of misconnections and other forms of disutility (e.g., loss of baggage). For this reason, the self-connecting market could represent an appealing area of interest for the insurance industry. Growth of insurers is not only required for existing markets, but also to access new ones. In this regard, air transportation could represent a gold mine given its expected high growth rates in the upcoming years [5, 19] and the existing presence of IT infrastructures, which could make the sale of insurance plans to passengers possible. Moreover, different from other categories of customers that have a limited understanding of the nature and purpose of insurance, air passengers are more prone to assess and manage risks due to two main reasons. On the one hand, flight anxiety is quite common, and potential passengers meticulously plan each aspect of the flight in order to ensure everything goes smoothly. On the other hand, missed flights may generate important transaction costs for both business and leisure passengers (i.e., phone calls with several airlines or insurance, no automatic rebooking on next connections), who may re-evaluate their plans in light of any potential reimbursement.

From a policy-level perspective, the fact that selfconnectivity has been increasingly recognized to be a valid alternative for passengers flying inside the European air transportation network accounting up to 2thirds of quickest connections within Europe, posits important challenges at a European level. Future European aviation strategies should depart from these evidences, being aware that full connectivity is only partially exploited still showing room for growth and improvement. Eventually, it should be however acknowledged that the majority of intra-European OD pax would (potentially) choose a direct flight (when available) as the best option to reach the destination, thus in part lessening the potential of self-connection in terms of market O\&D pax compared to its remarkable progress in connectivity. 


\section{Appendix 1}

Table 10 First 20 European hubs in terms of the total number of viable connections by type

\begin{tabular}{|c|c|c|c|c|c|c|c|c|}
\hline Rank & Hub Airport & OneWorld & SkyTeam & $\begin{array}{c}\text { Star } \\
\text { Alliance }\end{array}$ & Online & $\begin{array}{c}\text { Self } \\
\text { connect }\end{array}$ & Total & $\%$ Self \\
\hline 1 & Amsterdam-Schiphol & 43 & 37,479 & 72 & & 19,371 & 56,965 & $34.0 \%$ \\
\hline 2 & Frankfurt & 109 & 13 & 34,516 & 12 & 6396 & 41,046 & $15.6 \%$ \\
\hline 3 & Paris Charles De Gaulle & 67 & 18,087 & 62 & 1 & 12,694 & 30,911 & $41.1 \%$ \\
\hline 4 & London Heathrow & 16,546 & 33 & 449 & & 11,322 & 28,350 & $39.9 \%$ \\
\hline 5 & Madrid Barajas & 14,860 & 1105 & 4 & & 10,891 & 26,860 & $40.5 \%$ \\
\hline 6 & Munich F.J. Strauss & 130 & & 14,398 & 36 & 8499 & 23,063 & $36.9 \%$ \\
\hline 7 & Oslo & 15 & & 5813 & 115 & 12,041 & 17,984 & $67.0 \%$ \\
\hline 8 & Roma Fiumicino & 2 & 7617 & 28 & 2 & 8742 & 16,391 & $53.3 \%$ \\
\hline 9 & Stockholm-Arlanda & 16 & & 7464 & 130 & 8761 & 16,371 & $53.5 \%$ \\
\hline 10 & Copenhagen & & & 4980 & 31 & 7540 & 12,551 & $60.1 \%$ \\
\hline 11 & Helsinki-Vantaa & 8519 & & & 4 & 2522 & 11,045 & $22.8 \%$ \\
\hline 12 & Barcelona & 31 & 83 & 7 & & 8650 & 8771 & $98.6 \%$ \\
\hline 13 & London Gatwick & 452 & & 1 & 3 & 8152 & 8608 & $94.7 \%$ \\
\hline 14 & Zurich & 128 & & 5516 & 11 & 2011 & 7666 & $26.2 \%$ \\
\hline 15 & Brussels National & & 5 & 3850 & & 1925 & 5780 & $33.3 \%$ \\
\hline 16 & Paris Orly & 1 & 1058 & & 29 & 4520 & 5608 & $80.6 \%$ \\
\hline 17 & Dublin & 29 & & 4 & 1819 & 3036 & 4888 & $62.1 \%$ \\
\hline 18 & Manchester & 17 & & 2 & 6 & 4376 & 4401 & $99.4 \%$ \\
\hline 19 & Palma De Mallorca & 584 & 6 & & & 3620 & 4210 & $86.0 \%$ \\
\hline \multirow[t]{2}{*}{20} & London Stansted & & & & & 4090 & 4090 & $100.0 \%$ \\
\hline & European hubs & 44,725 & 66,661 & 79,785 & 5200 & 180,818 & 377,189 & $47.9 \%$ \\
\hline
\end{tabular}




\section{Appendix 2}

Table 11 First 20 European hubs in terms of number of extra-European viable connections by type

\begin{tabular}{|c|c|c|c|c|c|c|c|c|c|}
\hline Rank & Hub Airport & OneWorld & SkyTeam & $\begin{array}{c}\text { Star } \\
\text { Alliance }\end{array}$ & Online & $\begin{array}{c}\text { Self } \\
\text { connect }\end{array}$ & Total & Interc. \% & $\%$ Self \\
\hline 1 & London Heathrow & 11,086 & 33 & 400 & & 7497 & 19,016 & $67.1 \%$ & $39.4 \%$ \\
\hline 2 & Frankfurt & 86 & 13 & 15,060 & & 3650 & 18,809 & $45.8 \%$ & $19.4 \%$ \\
\hline 3 & Amsterdam-Schiphol & 21 & 12,219 & 53 & & 5110 & 17,403 & $30.6 \%$ & $29.4 \%$ \\
\hline 4 & Paris CDG & 60 & 9629 & 62 & 1 & 5998 & 15,750 & $51.0 \%$ & $38.1 \%$ \\
\hline 5 & Munich F.J. Strauss & 31 & & 4920 & & 2203 & 7154 & $31.0 \%$ & $30.8 \%$ \\
\hline 6 & Madrid Barajas & 3395 & 392 & 4 & & 2432 & 6223 & $23.2 \%$ & $39.1 \%$ \\
\hline 7 & Roma Fiumicino & & 2914 & 28 & & 2448 & 5390 & $32.9 \%$ & $45.4 \%$ \\
\hline 8 & Zurich & 41 & & 2701 & 3 & 768 & 3513 & $45.8 \%$ & $21.9 \%$ \\
\hline 9 & Helsinki-Vantaa & 1672 & & & & 318 & 1990 & $18.0 \%$ & $16.0 \%$ \\
\hline 10 & Copenhagen & & & 1003 & & 869 & 1872 & $14.9 \%$ & $46.4 \%$ \\
\hline 11 & Dublin & 26 & & 4 & 593 & 981 & 1604 & $32.8 \%$ & $61.2 \%$ \\
\hline 12 & London Gatwick & 138 & & & & 1126 & 1264 & $14.7 \%$ & $89.1 \%$ \\
\hline 13 & Stockholm-Arlanda & & & 729 & & 502 & 1231 & $7.5 \%$ & $40.8 \%$ \\
\hline 14 & Vienna & & & 602 & & 381 & 983 & $47.0 \%$ & $38.8 \%$ \\
\hline 15 & Barcelona & 25 & 24 & 7 & & 870 & 926 & $10.6 \%$ & $94.0 \%$ \\
\hline 16 & Dusseldorf & 425 & 5 & 31 & & 425 & 886 & $24.0 \%$ & $48.0 \%$ \\
\hline 17 & Oslo & & & 292 & & 489 & 781 & $4.3 \%$ & $62.6 \%$ \\
\hline 18 & Manchester & 17 & & 2 & 1 & 694 & 714 & $16.2 \%$ & $97.2 \%$ \\
\hline 19 & Brussels National & & 5 & 493 & & 185 & 683 & $11.8 \%$ & $27.1 \%$ \\
\hline \multirow[t]{2}{*}{20} & Milano Malpensa & & & 31 & & 555 & 586 & $40.7 \%$ & $94.7 \%$ \\
\hline & European hubs & 17,139 & 25,368 & 26,790 & 607 & 38,610 & 108,514 & $28.8 \%$ & $35.6 \%$ \\
\hline
\end{tabular}

\section{Abbreviations}

GDS: Global distribution systems; LCCs: Low-cost carriers; MCT: Minimum connecting time; MIDT: Marketing information data tapes; OAG: Official airline guide

\section{Acknowledgments}

We thank the participants at the 2017 Air Transport Research Society World Conference (ATRS) in Antwerp for useful discussions and helpful comments.

\section{Authors' contributions}

The work was a joint project of all authors. All authors read and approved the final manuscript.

\section{Funding}

Not applicable.

\section{Availability of data and materials}

Not applicable.

\section{Competing interests}

The authors declare that they have no competing interests.

Received: 5 May 2019 Accepted: 13 November 2019

Published online: 27 December 2019

\section{References}

1. Abdelghany, K. F., Abdelghany, A. F., \& Ekollu, G. (2008). An integrated decision support tool for airlines schedule recovery during irregular operations. European Journal of Operational Research, 185, 825-848.
2. Alamdari, F. (1999). Airline in-flight entertainment: The passengers' perspective. Journal of Air Transport Management, 5, 203-209.

3. Arikan, U., Gurel, S., \& Akturk, M. S. (2016). Integrated aircraft and passenger recovery with cruise time controllability. Annals of Operations Research, 236, 295-317.

4. Barnhart, C., \& Cohn, A. (2004). Airline schedule planning: Accomplishments and opportunities. Manufacturing and Service Operations Management, 6, 3-22.

5. Boeing. (2016). Current Market Outlook 2016-2035.

6. Bratu, S., \& Barnhart, C. (2006). Flight operations recovery: New approaches considering passenger recovery. Journal of Scheduling, 9, 279-298.

7. Burghouwt, G. (2007). Airline network development in Europe and its implications for airport planning. Ashgate Publishing, Ltd. https://scholar. google.it/scholar?q=Airline+network+development+in+Europe+and+its+ implications+for+airport+planning.+Ashgate+Publishing,+Ltd.\&hl=it\&as_ $s d t=0 \& a s \_v i s=1 \& o i=$ scholart

8. Burghouwt, G. (2012). Airline network development in Europe and its implications for airport planning. Airline Network Development in Europe and its Implications for Airport Planning.

9. Burghouwt, G., \& Redondi, R. (2013). Connectivity in air transport networks: An assessment of models and applications. Journal of Transport Economics and Policy, 47, 35-53.

10. Cattaneo, M., Malighetti, P., Paleari, S., \& Redondi, R. (2017). Evolution of the European network and implications for self-connection. Journal of Air Transport Management, 65, 18-28.

11. Cook, A., Tanner, G., Williams, V., \& Meise, G. (2009). Dynamic cost indexing-Managing airline delay costs. Journal of Air Transport Management, 15, 26-35.

12. Deshpande, V., \& Arıkan, M. (2012). The impact of airline flight schedules on flight delays. Manufacturing and Service Operations Management, 14, 423-440. 
13. Dobruszkes, F., Givoni, M., \& Vowles, T. (2017). Hello major airports, goodbye regional airports? Recent changes in European and US low-cost airline airport choice. Journal of Air Transport Management, 59, 50-62.

14. Duran, A. S., Gürel, S., \& Aktürk, M. S. (2015). Robust airline scheduling with controllable cruise times and chance constraints. IIE Transactions, 47(1), 64-83.

15. Evangelho, F., Huse, C., \& Linhares, A. (2005). Market entry of a low cost airline and impacts on the Brazilian business travelers. Journal of Air Transport Management, 11(2), 99-105.

16. Fichert, F., \& Klophaus, R. (2016). Self-connecting, codesharing and hubbing among European LCCs: From point-to-point to connections? Research in Transportation Business and Management, 21, 94-98.

17. Franke, M. (2004). Competition between network carriers and low-cost carriers-Retreat battle or breakthrough to a new level of efficiency? Journal of Air Transport Management, 10, 15-21.

18. Gopalan, R., \& Talluri, K. T. (1998). Mathematical models in airline schedule planning: A survey. Annals of Operations Research, 76, 155-185.

19. IATA (2016). IATA forecasts passenger demand to double over 20 years.

20. Jetzki, M. (2009). The propagation of air transport delays in Europe. Master's thesis, RWTH Aachen University, Airport and Air Transportation Research.

21. Kohl, N., Larsen, A., Larsen, J., Ross, A., \& Tiourine, S. (2007). Airline disruption management-Perspectives, experiences and outlook. Journal of Air Transport Management, 13, 149-162

22. Lan, S., Clarke, J.-P., \& Barnhart, C. (2006). Planning for robust airline operations: Optimizing aircraft routings and flight departure times to minimize passenger disruptions. Transportation Science, 40, 15-28.

23. Marla, L., Vaaben, B., \& Barnhart, C. (2011). Integrated disruption management and flight planning to trade off delays and fuel burn. Tech. Rep., DTU management, 2011.

24. Maertens, S., Pabst, H., \& Grimme, W. (2016). The scope for low-cost connecting services in Europe - Is self-hubbing only the beginning? Research in Transportation Business and Management, 21, 84-93.

25. Malighetti, P., Paleari, S., \& Redondi, R. (2008). Connectivity of the European airport network: "Self-help hubbing" and business implications. Journal of Air Transport Management, 14, 53-65.

26. Miller-Hooks, E., \& Patterson, S. S. (2004). On solving quickest time problems in time-dependent dynamic networks. Journal of Mathematical Modelling and Algorithms, 3, 39-71.

27. Redondi, R., Malighetti, P., \& Paleari, S. (2011). Hub competition and travel times in the world-wide airport network. Journal of Transport Geography, 19, 1260-1271.

28. Rebollo, J. J., \& Balakrishnan, H. (2014). Characterization and prediction of air traffic delays. Transportation research part C: Emerging technologies, 44, 231-241.

29. Suau-Sanchez, P., Voltes-Dorta, A., \& Rodríguez-Déniz, H. (2016). The role of London airports in providing connectivity for the UK: Regional dependence on foreign hubs. Journal of Transport Geography, 50, 94-104.

30. Suau-Sanchez, P., Voltes-Dorta, A., \& Rodríguez-Déniz, H. (2017). An assessment of the potential for self-connectivity at European airports in holiday markets. Tourism Management, 62, 54-64.

31. Zeigler, P., Pagliari, R., Suau-Sanchez, P., Malighetti, P., \& Redondi, R. (2017). Low-cost carrier entry at small European airports: Low-cost carrier effects on network connectivity and self-transfer potential. Journal of Transport Geography, 60, 68-79.

\section{Publisher's Note}

Springer Nature remains neutral with regard to jurisdictional claims in published maps and institutional affiliations.

\section{Submit your manuscript to a SpringerOpen ${ }^{\circ}$ journal and benefit from:}

- Convenient online submission

- Rigorous peer review

- Open access: articles freely available online

- High visibility within the field

- Retaining the copyright to your article

Submit your next manuscript at $\boldsymbol{\nabla}$ springeropen.com 